CASE STUDY

\title{
The Development of Contemporary Student Engagement Practices at the University of Winchester and Winchester Student Union, UK
}

\author{
Tom Lowe $^{\text {a* }}$, Cassie Shaw ${ }^{a}$, Stuart Sims ${ }^{a}$, Savannah King ${ }^{b}$, Angus Paddison ${ }^{c}$ \\ ${ }^{a}$ Academic Quality \& Development, University of Winchester, Winchester, United Kingdom. \\ ${ }^{\mathrm{b}}$ Marketing Department, University of Winchester, Winchester, United Kingdom. \\ ${ }^{\mathrm{c}}$ Faculty of Humanities and Social Sciences, University of Winchester, Winchester, United \\ Kingdom
}

*Contact: Tom.Lowe@winchester.ac.uk

\section{ABSTRACT}

This case study explores practice in four areas of student engagement activity which were developed in partnership between the University of Winchester and Winchester Student Union. The development, motivations, stakeholders, and challenges of activities built around the principles of representation, change, feedback, and research are discussed. Relationships between practices will be explored in the context of a proposal for how discrete practices can complement one another to create a community of partnership. The case study focuses on four key initiatives: Student Academic Representatives, Student Fellows Scheme, Student-Led Teaching Awards, and the Winchester Research Apprenticeship Programme. The four key initiatives are contextualised with a discussion of an ongoing project that seeks to provide greater coherence to student engagement through an institution-wide movement towards embedding partnership.

\section{KEYWORDS}

student engagement, partnership, students as partners, quality, student experience

In partnership with Winchester Student Union (WSU), the University of Winchester (UoW) is currently at a reflective plateau, reviewing four years' work in student engagement. From 2012, WSU and UoW stakeholders have pursued new opportunities where staff and students could work together. This work was influenced by literature and theory focused on 
working in partnership (Healey, Flint, \& Harrington, 2014; NUS, 2012). The institution sought engagement opportunities for students and staff to work collaboratively to enhance the student experience (Cook-Sather, Bovill, \& Felton, 2014; Wait \& Bols, 2015), by empowering students through models of change and representation (Dunne, 2016). A UoW and WSU staffstudent delegation attended the McMaster Institute for Innovation and Excellence in Teaching and Learning Students as Partners Summer Institute in May 2016 to revisit our practice. Earlier that year, UoW had been commended by the Quality Assurance Agency for Higher Education regarding practices in student engagement and partnership (QAA, 2012; 2016). The team were keen to take this time to establish how practice could be developed to sustain and enhance existing initiatives. This paper outlines core practices engaging students in representation, change, feedback, and research and is authored by those stakeholders who attended the Summer Institute and have been active at various levels of all the initiatives outlined below. This paper reflects on the extent of partnership of these practices, their development, the role of relevant stakeholders, and explores challenges and potential for developing our commitment to students as partners.

\section{REPRESENTATION}

Student academic representation at Winchester follows a familiar model of student representation in UK higher education, with the understanding that its "primary aim is to represent and defend the interests of the collective student body" (Klemenčič 2012). Student Academic Representatives (StARs) are volunteers coordinated by WSU to gather feedback and represent their cohort at meetings with academics and relevant professional services. Students elect WSU officers annually to represent the student body in several portfolios (e.g., education, welfare, communications) and govern WSU. Officers sit on key university committees (although not executive committees) representing students and lobbying for enhancement to the student experience.

The strong partnership between WSU and UoW has facilitated the creation of further opportunities for innovative student representation. This includes the Student Academic Council (SAC) where UoW senior managers, WSU officers, and students from each academic department discuss and influence cross-institution initiatives focused on student experience. This committee regularly funds student-support projects and campaigns. Students are also members of the panels which ensure that new and existing courses set appropriate academic standards, deliver an appropriate curriculum, and have robust student support in place. Student panel members are external to the course assessed, predominantly adding to this process by evaluating the student experience offered by the course.

Current quality assurance processes are reviewed by UK regulatory and funding bodies, and recent quality assurance protocols place a strong emphasis on student engagement. The new mechanism, conducted through Annual Provider Reviews (APR) (BIS, 2015), is likely to involve a new focus on student representation or statements. The structure of the partnership between the university and students involved in these representation activities can be unpacked through the see-saw of partnership below (Figure 1), indicating there is an unequal balance of participation in regards to representation in these initiatives. 
Challenges surrounding representation at any level of an institution include the fragility and inconsistency in a stakeholder's individual experience. Additional issues include student motivation to perform roles consistently and professionally, weighting of student voice, managing staff expectations, and logistical challenges in a wide-scale scheme with frequent turnover of students. Given the above challenges, the level of partnership in representation has potential to grow to a system where feedback is always voiced democratically and responded to effectively. However, the size of such schemes can limit the speed of development.

Increasing and enhancing the practices of representation to better the student experience is an ongoing goal shared by many Higher Education Institutions. At Winchester, this includes raising staff and student awareness and reviewing the accessibility of student feedback mechanisms of the StARS scheme. The officiality of student representation needs to continue to be built so StARs are a formal part of more processes at Winchester. This is particularly pertinent in the context of the emphasis UK higher education placed on the National Student Survey (NSS, 2016).

Figure 1: Representation weighting of staff-student partnership

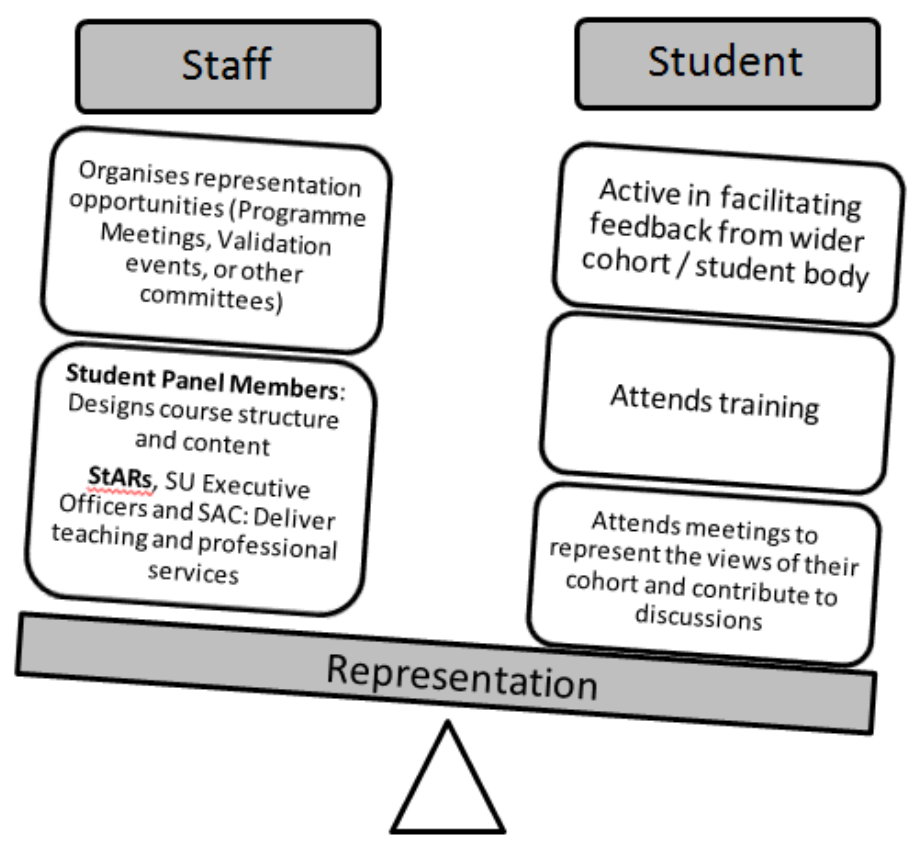

\section{CHANGE}

Moving beyond representation to more active roles, students participating in change are involved in actively shaping the direction of their experience. Kay and colleagues distinguish this from other forms of engagement: "They are engaged deeply with the institution and their subject areas, and the focus and direction" (Kay, Dunne, \& Hutchinson, 2010). In this spirit, the Student Fellows Scheme (SFS) is a partnership initiative, annually funding 60 students with a bursary of $£ 600$ enabling them to commit time to work with staff to enhance the experience of 
UoW students (Sims, Lowe, Hutber, \& Barnes, 2014; El-Hakim, King, Lowe, \& Sims, 2016). SFS runs across the academic year with ideas developed by students or staff or in partnership as depicted below (Figure 2).

Examples of projects from recent years include:

- Recognition and support for commuter students

- Interactive Law learning resources

- Redeveloping English literature online assessments

- Increasing access to performance and rehearsal spaces

The scheme is flexible, accommodating a wide range of projects to implement change. Various strategies include research, campaigns, resource development, and lobbying committees. Also, at the conclusion of SFS projects, students are asked to complete a feedback survey about their experiences. This encourages reflection on how they have developed and identifies key areas for development of the scheme.

Figure 2: SFS Weighting of balanced staff-student partnership projects

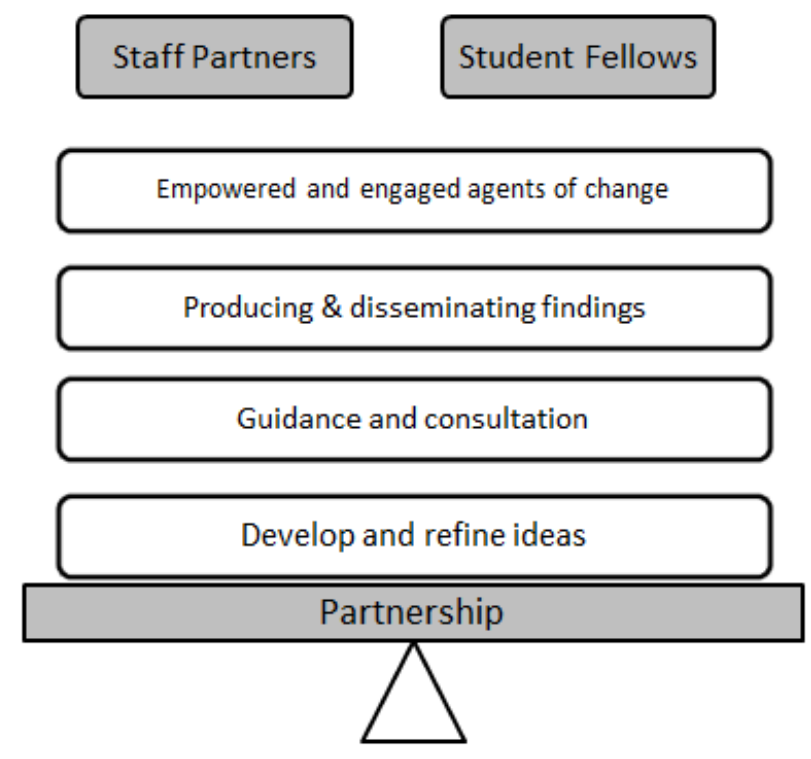

For the students themselves, the scheme offers a range of benefits including an increased sense of inclusion, pride, and support, as the following feedback quotes show:

"[Benefits included] opportunities to present, share, and discuss with influential members of the university, as well as at other institutions."

"Knowing that I have brought people together with a similar learning difference. Those people now know they aren't alone in how they feel." 
"The opportunity to devise and control our own research project (with supervision) was one of the most rewarding things we have ever done."

Fellows receive training and support in research methods, project management, and dissemination techniques to increase their project's effectiveness. Staff support students and contribute to change through their projects. The extent of partnership depends on how much time either party can commit but always requires a degree of mutual responsibility. While 50/50 partnership represents a minority of examples, experience has shown the occasions where partnership does not develop often is due to the idea only coming from one of the partners. For example, if a student developed the project focus and subsequently worked with a staff member to implement it, often the student takes more ownership of its direction. Projects developed and enacted in partnership often seem to have the smoothest working relationship, but this does not necessarily mean they have better outcomes. Some academic staff do not always immediately understand the importance of the partnership component of the scheme. This can lead to a range of models of practice from very student-led projects to staff being very prescriptive of student roles and behaviour. Some examples are represented below and above (Figures 2 and 3).

Figure 3: SFS weighting of unbalanced staff-student partnership projects

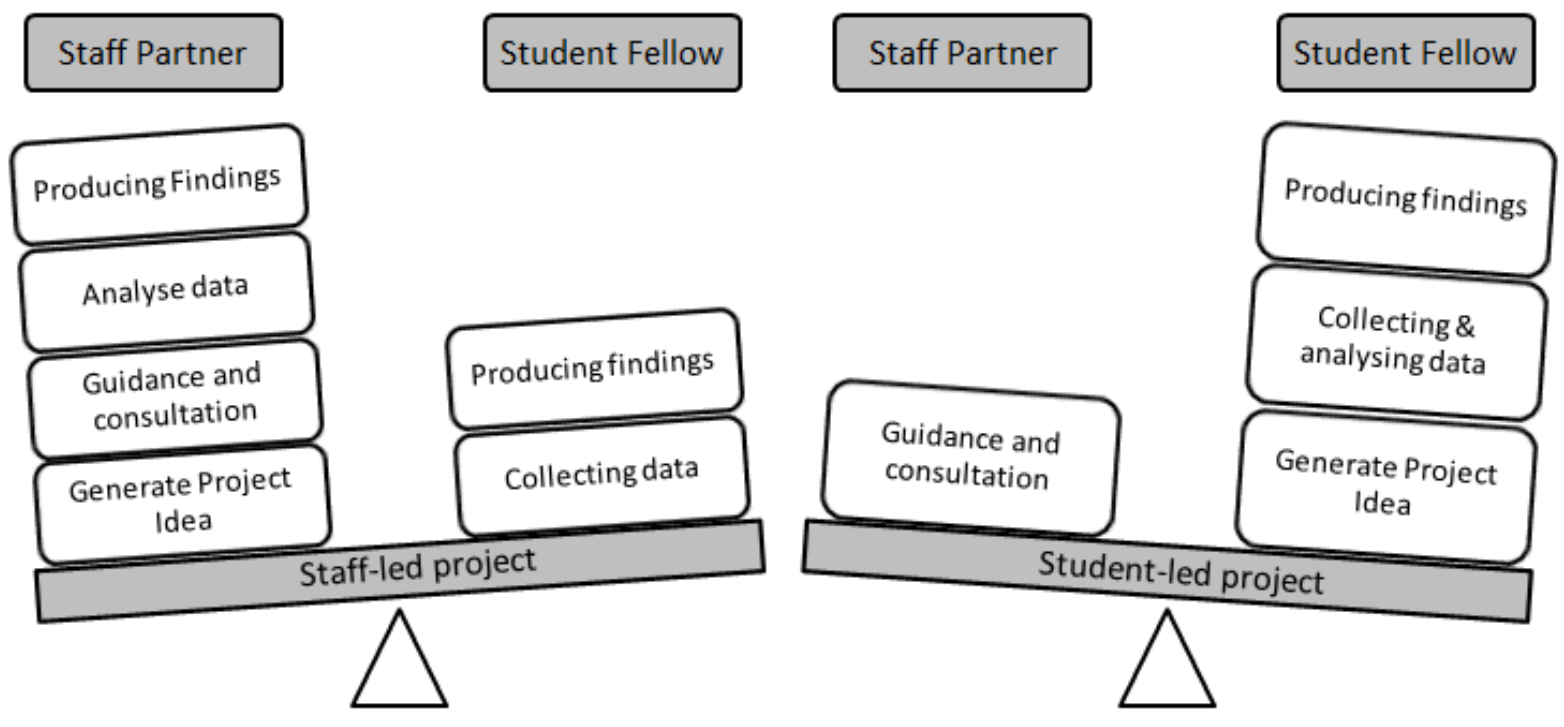

As a voluntary role, StARs can be restricted in directly making change. To address this and building upon the Feedback and Assessment for Students with Technology (FASTECH) where students were empowered as Fellows researching technology enhancement (Jessop et al., 2013), the SFS was developed by WSU and UoW to increase scope for students to be engaged directly in change processes. SFS has partnership embedded at every level. There is the overarching partnership of UoW and WSU, which co-funds the scheme. The scheme is managed in partnership between the WSU Vice President, Education and the UoW Research Officer, Student Engagement. Staff-student partnerships are also embedded in the committee

Lowe, T., Shaw, C., Sims, S., King, S., \& Paddison, A. (2017) The Development of Contemporary 5 Student Engagement Practices at the University of Winchester and Winchester Student Union. 
structure of the university with reporting of changes and outcomes occurring at course, department, and cross-institutional levels.

To ensure it supports UoW's learning community, SFS is evaluated annually in partnership with a Student Fellow. This annual evaluation process resulted in the following changes in 2016/17:

- Reworking the progress review system to include a written report

- Moving training materials online to increase accessibility

- Providing more feedback about projects in different parts of the institution

A key challenge of SFS is the size and scope of the initiative. Because Student Fellows are paid roles, the SFS can be restricted in terms of growth. While students receive a bursary for participating, staff volunteer their time. With increases in academic workloads (Kyvik, 2013) the sustainability of staff time and the continuation of funding are potential threats. A motivating factor behind SFS was to normalise students working with staff. There is a danger that investing in discrete activities such as SFS can situate partnership in a particular space of the institution which potentially constrains the development of wider staff-student collaboration. Though this practice was commended by the QAA, the team at the MIIETL Summer Institute were aware this was the only initiative at the institution built around equal partnership.

\section{FEEDBACK}

The Student-Led Teaching Awards (SLTAs) was a project borne from WSU and UoW's shared agenda to expand student feedback on best practice influencing the student experience. Feeding into a wider national agenda, SLTAs offer an opportunity to explore students' unique perceptions that help identify good practice and positively influence learning (HEA, 2012). SLTAs provide students with a platform to anonymously nominate any staff for excellence in a host of categories, which can support staff professional development and boost morale (Arthur, 2009). Every member of staff nominated for an award is notified. Students nominate in categories such as Inspirational Lecturer of the Year and Best Use of Resources (see Appendix 1 for SLTAs 2015-16 Awards Full List. A student committee organises the SLTAs, discussing the nomination process, organising an annual ceremony, and selecting winners based on qualitative submissions.

As seen in this case study, UoW students have opportunities to engage in representation, research, and change, but none have the ability to directly praise and commend staff for their work and support. Laced with positivity and praise, the SLTAs bridge the gap between staff and students in a way that was previously untapped. It also shares best practices at the institution amongst staff by highlighting innovative and inspirational staff members and the reasons why students are so inspired by them. Some anonymised examples of qualitative nominations for the 2015-2016 Most Inspirational Lecturer of the Year include:

"[The lecturer's] ability to make even the most challenging or mundane of concepts digestible and interesting is inspiring to any hopeful educator and a quality I aspire to emulate." 
"He provides continuous and incredible support for the students on his modules and prompts the development of their own ideas. I've never left a lecture by [him] without feeling like my whole perspective of the world has been shifted."

"She has gone, and continues to go, above and beyond her position as a lecturer; coaching, advising and inspiring me to reach my potential."

The key aspect to the SLTAs is its commitment to being student-led. The committee includes the WSU Vice President, Education, the Student Engagement Assistant, and students from across the institution who submit applications. Whilst this Student-Led project does not align distinctly with traditional notions of partnership, it does offer a valuable contribution to the institution as a student engagement initiative. The SLTAs are supported by senior members of management and staff across the institution, hinting towards the notion of partnership through its strong support from these key stakeholders. The SLTAs' relationship with partnership is explored below (Figure 4):

Funding for promotion and ceremony costs is bid for annually through the Student Academic Council (SAC). SAC has continued to approve funding for this project as a platform for positive student feedback and sharing of best practices.

Figure 4: SLTA weighting of staff-student partnership

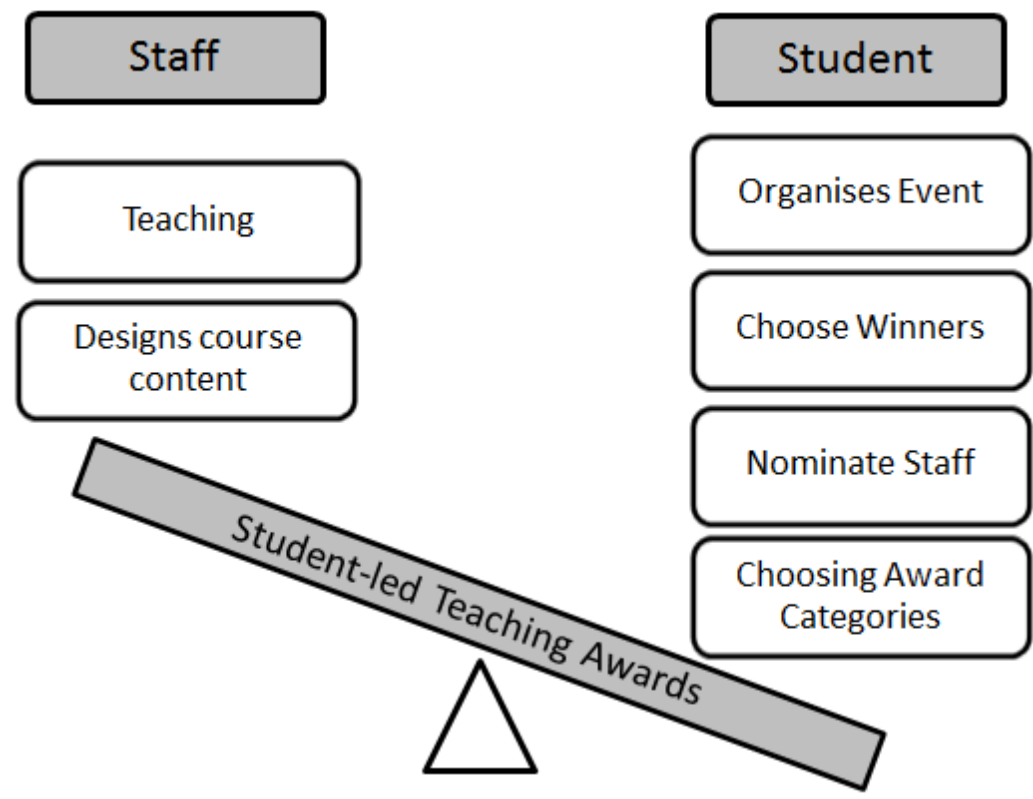

The sustainability of SLTAs is potentially a challenge, as WSU must bid annually to SAC in order to receive funding for the event. There is also another challenge due to the high WSU turnover of staff. The WSU Officers change annually by electoral process, so the SLTAs rest on the next Vice President Education's commitment to effectuate the SLTAs. Additionally, without a continuous source of funding, the support of the scheme will be annually problematic. The 
SLTAs must stay with the Vice President, Education, in order for it to be student-led, which is key to the scheme.

There are some challenges amongst staff regarding acceptance of the SLTAs. The notion of students being given the opportunity to award staff on their performance can be controversial amongst some. This is perhaps driven by the "terrors of performativity" (Ball, 2003) where staff feel academic freedom and values are being displaced by incentivised effectivity, which dominates over educational honesty (Ball, 2003). There is a perception that the SLTAs are a popularity contest, whereby the most entertaining staff member wins, rather than those conducting educationally purposeful academic work. The controversial nature of the SLTAs means that implementing such a scheme can be contentious (Madriaga \& Morley, 2016). Whilst there is opposition, the SLTAs provide a commendable accolade (in the form of both nominations and the award), which help to boost confidence and share best practices amongst staff. A review of the qualitative nominations indicates that students nominate staff for a wide range of reasons including entertainment, inspiration, and well-designed teaching and learning. The following nomination statement states that through the SLTAs students have an opportunity to recognise rigorous teaching that stretches them: "The project has aided me in taking a more analytical approach to my work and has offered me the opportunity to develop applied skills." From a manager's perspective, one of the interesting aspects of the SLTAs is how it provides evidence of the positive impact on students' learning experiences of various institutional strategies, from developing research-led and research-informed teaching to internationalising the curriculum. The SLTAs are a public, university-wide occasion recognising the impact of teaching on UoW students.

The SLTAs have grown every year in the number of nominations and attendees at the ceremony with still significant room to grow, given each student's eligibility to nominate. The possible number of nominations able to be cast by students still means that the SLTAs can grow further before it reaches its maximum potential. To ensure more students know about the SLTAs, a campaign of posters, merchandise, and class talks are planned each year. The longer the SLTAs are part of the annual celebration of UoW's staff, the more embedded the awards will become. Each year, as the quantity of award nominations grow and the number of award categories expands, more staff are contacted to congratulate them on their nomination. This means the SLTAs are reaching more members of staff to encourage their practice, which works to embed the culture of the SLTAs amongst them.

\section{RESEARCH}

Student involvement as researchers as a form of pedagogy has received increasing interest in recent years (Jenkins \& Healey, 2010). This can occur within and beyond the curriculum, often in specific spaces but contributing to greater knowledge of students' academic discipline (Hill \& Walkington, 2016). Piloted in one faculty in 2009, the Winchester Research Apprenticeship Programme (WRAP) was implemented cross-institutionally to enable undergraduates to work on a placement (of up to four weeks) on a research project alongside an academic. WRAP's origins came from a desire to provide more opportunities for students to become engaged in discipline-specific research and to encourage staff engagement with a research-informed teaching culture. Students participating in WRAP receive a weekly bursary to 
acknowledge the value of the work. Each faculty receives central funding with promotion and recruitment also carried out at the faculty level. WRAP has operated over 200 projects to date, engaging over 300 students since its inception.

The other initiatives outlined above prioritise engagement in the field of student experience and learning and teaching. WRAP, however, supports engagement within academic disciplines, attracting those wishing to gain experience in their field of study. WRAP can inspire undergraduate students to pursue postgraduate study. For example, in the Faculty of Arts, 34\% of WRAP students have remained at Winchester as postgraduates. Participation in WRAP can be motivated by the opportunity to receive remuneration. Also, due to the importance of current staff research interests in the success of WRAP, individual staff are key to sustainability, as are suitably engaged students.

WRAP's faculty-led organisation can lead to diverse promotional campaigns, timing and length of projects. This individual nature of WRAP means the students may not experience a cohesive community of practice unlike other student engagement initiatives. This can be seen as advantageous to the scheme by reflecting the specific needs of the faculty's students and staff. There is an individuality of student experience in WRAP because the nature of the projects are different in content. This raises difficulties when attempting to ensure a baseline experience for each student involved. Another potential difficulty is that there may not always be an appropriate academic research project aligned with every course. In terms of partnership and outputs, while the quality of the student contribution to research is often worthy of publication, student co-authoring has only occurred in a small number of cases. Walkington (2008, p. 41) identified that undergraduate researchers experience a "gap" not faced by academics due to a lack of wide dissemination, and Brew (2006) claimed this means undergraduates often feel "at arms length" from the research process. Another challenge is some academic staff have difficulties in developing a project in which students are genuinely partners, rather than assistants. This initiative's interaction with partnership is visualised below (Figure 5).

That said, student interest in WRAP continues to grow, indicating this scheme's potential to accommodate large numbers of projects. Steps are being taken for greater interaction between different staff and students involved in WRAP across the university, through promotion, celebration, and awareness.

\section{CONCLUSIONS}

This case study has explored the origins and potential of four key areas of student engagement activity developed in partnership at UoW with WSU. Throughout, the challenges of the four areas (representation, change, feedback, and research), their varying levels of staffstudent partnership, and their potential to be improved has been a central focus. Moving beyond individual sets of practice, new linkages between practices need to be explored where separate student engagement practices can complement one another, creating cohesion at the institution. At the MIIETL Institute, the authorial team concluded there was a need to act on these areas to further enhance student engagement practices through establishing a Centre for Student Engagement. 
Figure 5: WRAP weighting of staff-student partnership

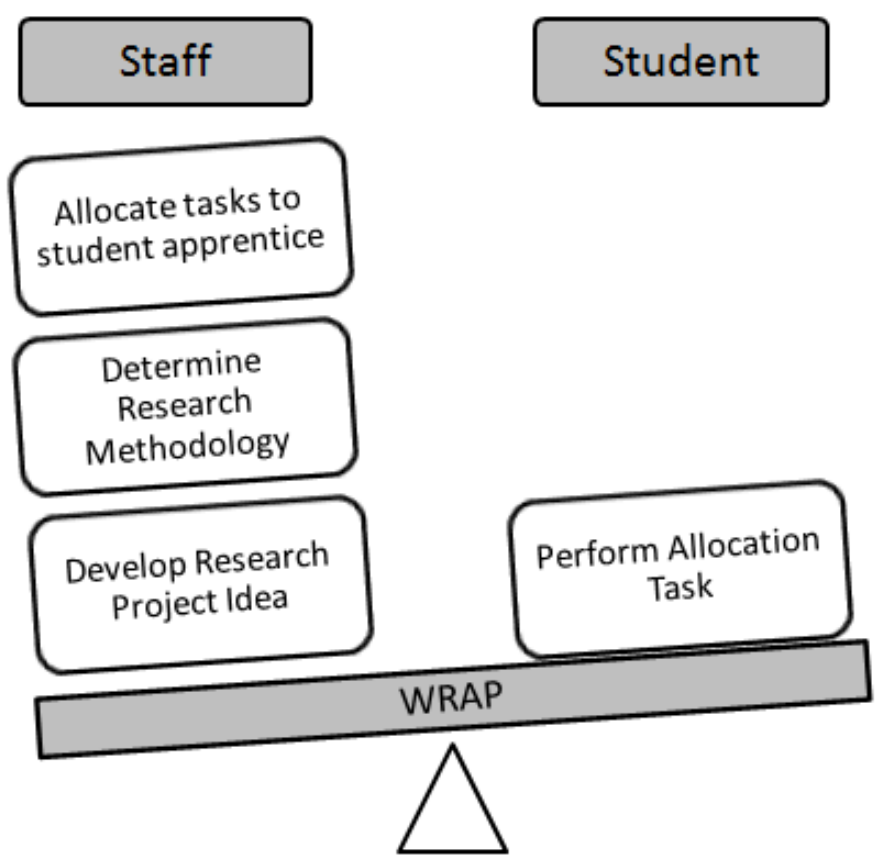

This proposal has been inspired by student-led research conducted as part of the Student Fellows Scheme that shows that students need greater clarity of purpose and knowledge of "where to go" to get more involved at UoW. Furthermore, a visible Centre would help staff struggling with aspects of the student partnership agenda (see the discussion of WRAP above) to have a stronger understanding of what engagement can look like. Some example quotes from this research included the following: "I think student engagement is very ambiguous" and "I find that the issue is that no one really knows where to go sometimes at uni" (Shaw, 2016). This corroborates wider research suggesting use of the term "student engagement" to be ambiguous and can lead to disengagement from students (Gibbs, 2014; Vuori, 2014). There is considerable partnership practice already occurring at UoW and WSU. Currently these practices all occur in discrete locations or places institutionally with a variety of structures. A place where these student engagement activities are accessible alongside each other will provide clarity of understanding and increase accessibility for students.

Such a Centre would aid in redressing the partnership balance of the university's portfolio of student engagement initiatives. As explored, not every student engagement partnership activity operates with a 50/50 equal partnership between student and staff or the Student Union and institution. However, in reviewing our own practices throughout this case study, we have become increasingly confident that 50/50 partnership is not always necessary for partnership to work more broadly. The natural inclinations of some engagement initiatives to lend themselves to a weighting in favour of students or staff works well when offered alongside schemes with the alternative weighting. In doing so, Winchester's culture of student 
engagement as a whole is contributing to the partnership aim, rather than one discrete activity adopting this mantle.

The team foresee a Centre for Student Engagement providing this student-facing service designed to increase participation in extra-curricular and co-curricular activities supported by research. Winchester can also continue at the forefront of developing new activities to enhance the student experience, by linking the above opportunities and expanding practice in student engagement.

\section{NOTES ON CONTRIBUTORS}

Tom Lowe is the Project Manager of the HEFCE Catalyst funded programme REACT (Realising Engagement through Active Culture Transformation) at the University of Winchester. Tom is also the Secretary of RAISE and previously the Vice President, Education at Winchester Student Union 2013-15.

Cassie Shaw is the Research Officer (Student Engagement) and REACT Researcher at the University of Winchester. Cassie also co-directs the Student Fellows Scheme. Previously Cassie was the Student Engagement Assistant at Winchester Student Union and co-ordinated the Student Academic Representatives and the Student Led Teaching Awards.

Dr Stuart Sims is Head of Student Engagement and Research \& Teaching Fellow based in Academic Quality \& Development at the University of Winchester. He is also Senior Researcher on the REACT project.

Savannah King is the Student and Alumni Communications Officer at the University of Winchester. At the time of these activities, she was the President of Winchester Student Union where she had previously served as the International Students Officer.

Dr Angus Paddison is the Acting Dean of the Faculty of Humanities and Social Sciences \& Reader in Theology at the University of Winchester. At the time of these activities he was the Director of Academic Quality and Development for the University.

\section{REFERENCES}

Arthur, L. (2009). From performativity to professionalism: Lecturers' responses to student feedback. Teaching in Higher Education, 14(4), 441-454.

Ball, S. J. (2003). The teacher's soul and the terrors of performativity. Journal of Education Policy, 18(2), 215-228.

Brew, A. (2006). Research and teaching: Beyond the divide. London: Palgrave Macmillan.

Cook-Sather, A., Bovill, C., \& Felton, P. (2014). Engaging students as partners in learning and teaching: A guide for faculty. New York: Jossey-Bass. 
Department of Business, Innovation, and Skills [BIS], (2016). Success as a knowledge economy: Teaching excellence, social mobility, and student choice (Policy Paper). Retrieved from https://www.gov.uk/government/publications/higher-education-success-as-aknowledge-economy-white-paper

Dunne, E. (2016). Design thinking: A framework for student engagement? A personal view. Journal of Educational Innovation, Partnership and Change, 2(1).

El Hakim, Y., King, S., Lowe, T., \& Sims, S. (2016). Evaluating partnership and impact in the first year of the Student Fellows Scheme. Journal of Educational Innovation, Partnership and Change, 2(1).

FASTECH. (2016). Feedback and assessment for students with technology. Retrieved from http://jiscdesignstudio.pbworks.com/w/page/51251270/FASTECH\%20Project

Gibbs, G (2014, May 1). Student engagement, the latest buzzword. Times Higher Education. Retrieved from https://www.timeshighereducation.com/news/student-engagementthe-latest-buzzword/2012947.article

Higher Education Academy (HEA). Student Led Teaching Awards. Retrieved from: http://www.studentledteachingawards.org.uk/

HEA. (2014). Framework for partnership in learning and teaching in higher education York: Higher Education Academy. Retrieved from: https://www.heacademy.ac.uk/studentspartners-framework-action

Healey, M., Flint, A., \& Harrington, K. (2014). Engagement through partnership: Students as partners in learning and teaching in higher education. York: Higher Education Academy.

Hill, J. \& Walkington, H. (2016). Developing graduate attributes through participation in undergraduate research conferences. Journal of Geography in Higher Education, 40(2), 222-237.

Kay, J., Dunne, E., \& Hutchinson, J. (2010). Rethinking the values of higher education: Students as change agents? Gloucester: The Quality Assurance Agency for Higher Education.

Retrieved from: http://dera.ioe.ac.uk/1193/

Kyvik, S., (2013). The academic researcher role: Enhancing expectations and improved performance. Higher Education, 65(4), 525-538.

Jenkins, A. \& Healey, M. (2010). Undergraduate research and international initiatives to link teaching and research. Council on Undergraduate Research Quarterly, 30(3), 36-42.

Klemenčič, M. (2012). Student representation in Western Europe: Introduction to the special issue. European Journal of Higher Education, 2(1), 2-19.

Madriaga, M. \& Morley, K. (2016). Awarding teaching excellence: "What is it supposed to achieve?" Teaching in Higher Education, 21(2), 166-174.

National Student Survey (NSS). (2016). Retrieved from http://www.thestudentsurvey.com/about.php

National Union of Students (NUS). (2012). A manifesto for partnership. Retrieved from http://www.nusconnect.org.uk/resources/a-manifesto-for-partnership

Quality Assurance Agency (QAA). (2012). UK quality code for higher education. Gloucester: Quality Assurance Agency.

QAA. (2016). Higher Education Review: University of Winchester. Retrieved from: http://www.qaa.ac.uk/reviews-and-reports/provider?UKPRN=10003614\#.WQIHJtL1AdU 
Shaw, C. (2016, May). Student perceptions of "student engagement" at the University of Winchester. Paper presented at the Winchester Student Fellows Conference 2016, University of Winchester.

Sims, S., Lowe T., Barnes, G., \& Hutber, L. (2014). The Student Fellows Scheme: A partnership between the University of Winchester and Winchester Student Union. Educational Developments, 15(3), 7-10.

Vuori, J. (2014). Student engagement: Buzzword or fuzzword? Journal of Higher Education Policy and Management, 36(5), 509-519.

Wait, R. \& Bols, A. (2015). Making student engagement a reality: Turning theory into practice (Report). Retrieved from the GuildHE website http://www.guildhe.ac.uk/blog/makingstudent-engagement-a-reality-turning-theory-into-practice/

Walkington, H. (2008). Geoverse: Piloting a national e-journal of undergraduate research in Geography. Planet, 20, 41-46. 